\title{
TUDO QUE SE MOVE É CAÇA
}

\section{EVERYTHING THAT MOVES IS HUNTING}

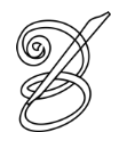

Autora:

María Teresa Andruetto

Traduzido por:

Nylcéa Thereza de Siqueira PEDRA*

Universidade Federal do Paraná

Curitiba, Paraná, Brasil

Resumo: María Teresa Andruetto é dona de um universo ficcional bastante rico. Saindo da llanura argentina, seus escritos reverberam pelo mundo. O conto "Tudo que se move é caça", faz parte do conjunto de treze contos que formam o livro Caça. Nos contos que compõem a obra, a autora explora a vida de mulheres, sejam elas caçadoras, vítimas ou traidoras. $\mathrm{O}$ conto que se lê em tradução a continuação pode ser recebido como uma grande metáfora. Na cozinha de Diana, Verena e Galia se cozinham os ingredientes que certamente convidarão o leitor a uma reflexão à primeira vista inesperada.

Palavras-chave: María Teresa Andruetto. Literatura argentina. Conto. Tradução. Mulheres.

Abstract: María Teresa Andruetto owns a very rich fictional universe. Leaving Argentine's llanura, her writings eco around the world. The story "Everything that moves is hunting, is a set of thirteen short stories that are part of the book Caça. In these short stories, the author explores the lives of women, whether they are hunters, victims or traitors. This short story that is presented below in a translated version, can be received as a great metaphor. In Verena, Galia and Diana's kitchen, the ingredients that will certainly invite the reader to an unexpected reflection are being cooked.

Keywords: María Teresa Andruetto. Argentine literature. Short story. Translation. Women.

RECEBIDO EM: 16 de setembro de 2019

ACEITO EM: 26 de fevereiro 2020

PUBLICADO EM: março 2020 
$\mathrm{M}$ aría Teresa Andruetto ${ }^{1}$ (1954) nasceu em Arroyo Cabral, província de Córdoba, na Argentina. Delimitar o espaço geográfico do seu nascimento não é um preciosismo de quem a apresenta, pois o lugar de onde vem, a sua terra, a sua língua e os seus, são essenciais para a compreensão de sua obra. Ainda que os diversos prêmios, especialmente o Hans Christian Andersen (2012), recebido pelo conjunto de sua produção literária infanto-juvenil, falem de uma autora prolixa e prestigiosa, Andruetto é bastante modesta ao falar de si mesma. Quando perguntada sobre a sua trajetória como escritora, costuma responder que primeiro teve leitores e, depois, livros. Tal afirmativa rememora o percurso da autora que, antes de consagrar-se, chegou a coordenar sete turmas de escrita criativa em uma mesma semana. Ainda no universo dos leitores, seu nome vai além da geografia argentina e é uma das grandes referências mundiais na discussão da formação de novos leitores. No que cabe à sua produção literária, que começa a ser publicada em 1993, transita entre o teatro, a poesia e a prosa. Apesar de defender uma literatura sem adjetivos, as suas obras infanto-juvenis são muito celebradas e algumas delas foram traduzidas para o português por Marina Colasanti. No entanto, se o sucesso de um autor se mede pelas vezes que a sua obra é lida, adaptada ou visitada, há uma longa lista de adaptações, espetáculos e traduções de suas obras. Sua última publicação é o livro-álbum Clara y el hombre de la ventana (2019) em parceria com a ilustradora Martina Trach. Das montanhas de Córdoba se ouve a voz da menina-autora que tem os pés firmes na sua terra, mas a cabeça em todos os lugares: coragem! 


\title{
TUDO QUE SE MOVE É CAÇA
}

\author{
para Inés Vásquez \\ o universo é um lusco-fusco \\ andante bosquel onde tudo o \\ que se move é caça. \\ AMELIA BIAGIONI
}

Diana tinha redigido o anúncio quatro noites antes, enquanto Galia decorava a casa e Verena acertava os detalhes do cardápio. Desde o começo foi assim: Verena se ocupava dos assuntos da cozinha e da maceração das carnes com temperos e conjuros que tinha aprendido nas Missões Africanas. Às vezes, Galia ajudava na preparação dos pratos, mas nunca na do prato principal; ali só quem se arriscava era Verena, que tinha estado na Boca do Ocre, às margens do rio das Mortes, e chegado até Niamey para aprender entre os selvagens - quase morta debaixo do sol - a condimentar carnes de caça.

Galia tinha morado algum tempo em Matadi, Catanga e Port Étienne. Diana, por sua vez, só tinha feito um cruzeiro por Molucas e - já embarcada no projeto - percorreu Tricomalee e Calamianas com o propósito de se aperfeiçoar nas maneiras de abordar a presa; mas nenhuma das duas aprendeu a cozinhar como Verena. A habilidade que Verena demonstrava na cozinha levou Diana a se ocupar das relações públicas e das questões de caça - intensa, febril - e Galia, que tinha um gosto refinado e era parente das pessoas mais ilustres de Buenos Aires, a se encarregar da decoração das salas e também do atendimento personalizado às clientes, marca distintiva do clube.

As três haviam desejado seguir outros rumos. Intensamente haviam desejado, mas, como no poema preferido de Diana, os diversos labirintos de passos que suas vidas teceram desde um dia qualquer da infância terminaram por conduzi-las àquela decisão. Sempre tinham sido mulheres enérgicas, ávidas por conhecer tradições insólitas, costumes que em alguma ocasião seriam proveitosos. Mas foi Galia quem teve a ideia, quem convidou as amigas de infância, no começo dos anos 1980, para fundar o clube. Antes disso, as três tinham militado em movimentos de mulheres e era isso, mais do que qualquer outra coisa, o que sustentava o projeto.

Já no começo, em conjunto, decidiram camuflar as atividades sob a forma de um serviço de acompanhantes gordas, e não poderia ter existido melhor subterfúgio, como logo puderam comprovar; mas não se tratava de um serviço de acompanhantes, era, na verdade, um 
clube com sócias, cobrança rigorosa de mensalidades, cerimônias de iniciação e ritos de passagem, e que oferecia, entre outras comodidades, sauna, salão de beleza, sala de massagem e, como razão de sua existência, um restaurante exclusivo. Se alguém telefonasse procurando uma gorda ou, ainda que dissimuladamente, deixasse entrever seu desejo de encontrá-la, elas colocavam a máquina para funcionar. Trabalharam assim durante meses, de um modo privado, secreto, para satisfazer a demanda de amigas e conhecidas, até que a matéria-prima foi insuficiente e se viram obrigadas a anunciar o serviço.

O anúncio dizia: Acompanhantes gordas. Gordas dispostas a tudo. Diana achou que soava bem e que muita gente se interessaria pela oferta. Muito tempo antes, as três haviam descoberto que há um tipo de homem que gosta de mulheres gordas e as encara entre o fetichismo e o voyeurismo. Mas, ao chegar aos quarenta, descobriram as delícias da vida sibarítica e elaboraram um cardápio rigoroso de comidas nas quais não faltavam macadâmia, coco, castanha de caju e molhos engrossados com creme de leite, com o propósito de engordar pelo menos sessenta quilos em um ano. Ganhar peso, tanto peso assim, não foi - como de início acreditaram que seria - uma tarefa fácil. Cada uma a seu modo tinha passado vinte anos 298 fazendo regimes, à procura de amores duradouros; até que tomaram consciência e decidiram mudar radicalmente de vida. Trocar tudo aquilo por amêndoas, chocolates, vitaminas de banana com leite e sanduíches de presunto cru com manteiga. Não mais escravas da balança, livres para engordar sem limites, ganharam rapidamente entre vinte e trinta quilos, e por aí ficaram, sem conseguir achar um modo de levar o sobrepeso a sessenta, setenta, que era o necessário para, em forma, lançarem o serviço de acompanhantes e abrirem o clube para a clientela.

Tentaram com creme de avelã e mel no café da manhã. Acostumaram-se a interromper o sono com lanchinhos. Colocavam o despertador para as três, cinco e sete horas e tateavam no escuro os bombons de licor, as trufas, os chocolates em barra que tinham deixado em cima do criado mudo. De manhã, devoravam azeitonas pretas, provolones, pães com pasta de anchovas, com paté, com roquefort, com manteiga, e se entupiam de torresmo que a empregada lhes trazia do campo.

Propuseram-se a engordar pelo menos três quilos por semana, de modo a não atrasar os preparativos para a inauguração e, em alguns meses - no máximo em um ano -, ter condições de abrir um restaurante que se tornaria a principal atração, o ponto alto do clube. Mas o que no começo parecia tão fácil acabou se tornando uma tarefa que custou muito mais tempo e esforço do que o previsto. Engordaram o necessário somente quando decidiram 
comer aquelas carnes de caça, alcançando o peso indicado nos manuais e atingindo um grau estranho de beleza - pele e olhos luminosos - com aquele olhar selvagem dos anúncios publicitários que se transformou no atrativo mais notável do clube.

Decidiram chamar o prato de manjar proibido, ainda que no cardápio aparecesse como Carne vermelha de caça às finas ervas. Verena tinha experimentado pela primeira vez no Congo Belga, e depois conheceu outras versões na Guiné Conacri e no Níger. Desde então, tinha tentado várias combinações de ingredientes e condimentos até encontrar o sabor que o caracterizava, um sabor contundente e delicado ao mesmo tempo, que as sócias saberiam apreciar. Certa tarde, tendo conseguido uma peça de carne, experimentaram fazer uma versão com canela e concordaram que apenas aquele ingrediente não ficava bom, mas que uma pitada era necessária, e que não devia levar muito limão, pois a acidez ofuscava o elemento base. Cada ingrediente - fosse sálvia, estragão ou massala - precisava ser degustado várias vezes e assim, quase sem se dar conta, elas foram alcançando o peso necessário. Logo perceberam que o estragão não era tempero para um prato como aquele: tratava-se de erva para preparações suaves, legumes, peixes talvez, nunca cairia bem com o prato pesado que ali era o objetivo. A primeira a perceber isso foi Galia. Descobriu que o alecrim era a erva adequada porque o seu sabor bem definido fazia frente ao da carne, e que a páprica e o gengibre lhe davam um toque exótico e, além disso, avivavam e tornavam inconfundíveis os elementos. Também foi Galia quem percebeu que os melhores acompanhamentos eram os chutneys - especialmente o de pera - e o molho de ameixas que tanto combinava bem com aquela carne como com a de porco. Foi ela, ainda, a primeira a descobrir que, com as numerosas degustações, tinham engordado mais do que com os bombons, os chocolates em barra e a nutella que importavam em grande quantidade de Milão.

Estavam dispostas a levar o tempo que fosse preciso até abrir esse restaurante exclusivo, para mulheres selecionadas de maneira meticulosa, mas com aquela descoberta não foi preciso esperar muito, pois tudo aconteceu muito naturalmente. Em poucos meses, cada uma engordou mais de oitenta quilos e, assim, alcançados os requisitos fixados no regulamento, pouco a pouco trataram de estabelecer um hábito, um modo de canalizar os impulsos, de trazer os homens até elas, ávidas por começar a se dar alguns agrados.

Naquela manhã, receberam desde cedo algumas ligações - quase todas de fornecedores - que não tinham nada a ver com o assunto, até que a secretária veio dizer que ligavam a respeito do anúncio e passou o telefone para Diana. Quando alguém pedia uma gorda, ou quando elas suspeitavam que por trás de uma conversa havia tal interesse, 
começavam a tramar. Tratava-se de um procedimento minucioso porque era preciso passar a peneira, realizar um processo escrupuloso de seleção, até depurar a demanda e ficar apenas com os homens de necessidades mais ancestrais. Primeiro procediam a uma longa conversa telefônica para esclarecer dúvidas e averiguar de que natureza era o desejo, pois, se tinha uma coisa da qual se orgulhavam, era a de satisfazer plenamente a clientela. Uma vez terminado o contato telefônico, vinha uma primeira aproximação, às vezes a única, com um questionário que incluía certos tópicos, como averiguar se eram casados ou se a mãe estava viva (de todas, a pergunta mais viscosa); averiguações que pareciam sem sentido, mas que tinham importância singular. Tudo conduzia a uma espécie de aquecimento e, se o cliente respondesse bem, se tivesse - como elas esperavam - um desejo descontrolado, então Diana combinava um encontro íntimo. Havia certa gratuidade naquilo tudo (ainda que um pouco de dinheiro sempre fosse necessário para recuperar o investimento) e as coisas funcionavam entre elas como uma confraria, com uma convicção similar à dos poetas mais extravagantes ou à dos membros de uma comunidade religiosa. Para dizer de outro modo, elas compreenderam rapidamente que a beleza é sempre horrorosa. Não por acaso o lema do clube era uma frase de Nietzsche escrita em letras góticas por cima da porta de entrada do restaurante: Que tudo te aconteça, o belo e o terrível. Tinham levado o sentido dessa frase ao extremo, fazendo com que cada um dos exemplares seduzidos a experimentasse vivamente. Não pensavam aceitar meninos, procuravam homens feitos, foi uma coisa que pactuaram desde o começo. Os fracos, os pusilânimes, não eram destinatários dignos de seus esforços. A missão que desenvolviam - pensaram certa vez - era parecida a um esporte, à pesca da truta, por exemplo, na qual a habilidade da presa, sua resistência, aumenta o prazer do pescador. E, por estranho que possa parecer, era isso que os fazia cair na rede: ninguém desejava ser menos, todos contavam vantagem da quantidade de mulheres que haviam tido, alguns chegavam a dizer que em sua coleção só faltava uma gorda, e se vangloriavam com detalhes de mau gosto sobre o estado em que tinham deixado as mulheres seduzidas, ou contavam mentiras que as irritavam: que ninguém os compreendia e menos ainda as mães de seus filhos.

Inicialmente, somente as proprietárias trabalhavam como acompanhantes, ainda que em algumas ocasiões, se necessário, convocassem as sócias do clube, mulheres de gordura incipiente ou já consideravelmente gordas, as genuínas destinatárias do projeto, recrutadas havia tempo para a causa.

O homem disse a Diana que queria contratar uma gorda. Quando ela perguntou que medidas lhe interessavam, maneiras preferidas de abordagem carnal, dados de seu histórico 
com gordas, experiências anteriores com bulímicas, anoréxicas e mulheres com outras alterações de conduta alimentar, ele gaguejou, disse que não tinha imaginado que teria que dar tantas explicações. Ela esclareceu que todas as perguntas eram feitas com o propósito de oferecer o melhor serviço, o mais adequado às necessidades de cada cliente, e foi então que ele soltou a primeira confissão: era casado com uma mulher que só comia laranja e queijo branco e fazia seis horas de bicicleta por dia. Tossiu nervoso e disse que sempre tinha desejado ver como come uma gorda; disse também outras coisas, o que dizem todos, que ela já está acostumada.

Diana logo percebeu que aquele homem era um grosseiro, como quase todos os que ligavam procurando gordas. Ele disse coisas que ela guardou cuidadosamente na memória, mesmo não tendo vontade de reproduzi-las mais tarde para as sócias; disse também que estava procurando por aquilo há meses e finalmente perguntou quanto cobravam pelo serviço; foi quando ela soube que ele tinha mordido a isca. Não estranha que ele lhe pergunte quanto pesa, porque ele não conhece os contratos, mas o cumprimento das regras era estritamente observado: ela jamais, por nenhum motivo, revelará seu peso, sabe que essa negativa estimula o desejo. Ele ficou em silêncio do outro lado da linha, até que ela mencionou as ofertas especiais para homens com mulheres anoréxicas, e foi isso que o fez se decidir.

Diana combinou de encontrá-lo na Confeitaria do Moinho; disse que estaria lá às sete e que pediria um chá. Quando ele desliga, ela vai até o quarto e procura a roupa íntima de renda feita sob medida. Verifica se as alças do sutiã são suficientemente fortes, porque alguns homens se fazem de desajeitados. Escolhe cuidadosamente o que vai vestir; experimenta a calça malva estampada, a pantalona e o sobretudo lilás, mas se decide pelo vestido turquesa, porque sabe que aquele é o tipo de homem que gosta de emoções fortes, de cores chamativas, de decotes expondo a carne branca.

Há três mesas ocupadas àquela hora da tarde, na Confeitaria do Moinho. De uma delas, um homem magro, insignificante, olha para ela. $\mathrm{O}$ homem manda, pelo garçom, um papelzinho para Diana; o bilhete diz para ela pedir alguma coisa, o que quiser. Diana adora tortas, principalmente as de castanha e pede um pedaço. Come voluptuosamente. O homem escreve para que ela coma mais, para que continue comendo. Ela gosta dos doces expostos no balcão: um pudim de claras, um tiramisu, uma floresta negra, uma torta de coco. O garçom sugere a de coco, com o lembrete de que é a especialidade da casa. Diana responde que prefere um folhado, porque pode lamber o doce de leite. 
Ela sabe que deve continuar com o jogo até o final, excitando-o até o extremo de leválo para o clube. Ele pede que coma com as mãos, que chupe os dedos e que, quando estiver chupando os dedos, olhe para ele. Ela diz que para chupar os dedos o preço é outro, que tem uma taxa extra, mas faz o que ele pede, deixa que ele ganhe.

Mais tarde, o homem manda que ela vá ao banheiro e solte a cinta elástica, porque ele não gosta de gordas atadas. Ela vai, tira a cinta e respira livremente: não é ruim que alguém a queira assim. Algo lhe passa pela cabeça por um momento, pensa em um garoto que conheceu no segundo ano do ensino médio. Afasta logo o sentimento, nada pode distraí-la da causa que abraçou, dos propósitos traçados para o clube. Olha-se no espelho e passa a língua pelos lábios; em seguida se recosta à parede, desce devagar a mão pelas carnes soltas e continua descendo até a fenda úmida — e vermelha como uma flor de carne — pensando naquele garoto que se chamava Pablo e na tarde em que se amaram atrás de uma parede por onde trepavam essas flores brancas chamadas Damas da Noite. Sabe que lá fora, sentado no salão, está o homem que a contratou e que paga para que ela esteja ali, naquele estado, e depois conte para ele. E assim é, sai do banheiro, vai até a mesa e escreve em um papel o que fez,

302 escreve que o fez pensando nele e que, por favor, ele a leve para algum lugar onde possam ficar a sós.

Ele se aproxima da mesa, senta-se diante dela e diz, sorrindo, que tinha pagado para vê-la comer - esse era o combinado - mas que aceitaria ver como ela se despe, como fica de roupa íntima. Ela entende rapidamente que as coisas estão chegando ao ponto desejado, um ponto sem retorno. No caminho, ele tenta tocá-la, mas ela não deixa; depois o sujeito pergunta coisas, o que perguntam todos. Gente dessa laia, com suas perguntas e afetações, a cansam; nem sempre responde, mas agora diz algo próximo à verdade: são três as donas do negócio, as outras são sócias e se trata de um lugar exclusivo para mulheres. Contou porque o homem lhe inspirava alguma confiança, como se fosse sem querer, disse que se aventuravam em formas de prazer pouco usuais, algumas — ela acreditava — exclusivas da casa, já que não apareciam nem no Kama Sutra.

Diana viu como ele se acomodava no banco, com cara de satisfeito; tomou da mão dela e começou a beijá-la, babando-se. Estava tão ridículo, quase sumindo no fundo do assento, que parecia um boneco. Imaginou-o em cima dela: um fantoche sobre seu corpo enorme, tentando satisfazê-la. Então ele começou a falar, não parou de dizer que sua mulher estava internada, que sempre tinha sido seletiva com a comida, que cozinhava sem azeite em frigideiras de teflon e, se saísse da dieta, se castigava com cem flexões para compensar, mas 
que, até o dia em que a levaram de ambulância para o hospital, nem ele nem ninguém tinha percebido que ela fazia seis horas de bicicleta por dia e estava doente de tão magra. Também disse que não imaginava como as coisas iam acabar, mas que teve uma imensa vontade de transar com uma gorda porque merecia uma desforra. Eufórico, colocou a mão na perna de Diana. Ela levou a mão delicadamente até a coxa dele e a deixou ali, respondendo que para ela também seria um prazer.

A sala era um lugar asséptico, lembrava um pouco um hospital. Tinha um grande sofá branco, uma chaise longue, algumas almofadas no chão e janelões que davam para o pátio interno, com grossas cortinas brancas. Apenas um tapete de juta e alguns artesanatos orientais revelavam as viagens e a rica experiência de suas donas.

Diana conduziu delicadamente o homem até o sofá, serviu-lhe uma bebida e colocou música. El amor brujo combinava com a ocasião. Tinham muitas gravações, mas pôs para tocar a de um trio de mulheres, uma versão pouco ortodoxa pontuada, ao fundo, por um melodioso dueto de flautas. Desabotoou o vestido e o colocou sobre a chaise longue, depois tirou o sutiã e despontaram, livres enfim, os peitos, mamilos claros de quem nunca amamentou, e a calcinha de renda vermelha oculta por baixo de uma sobressaia de carne leitosa. Então dançou para ele e deixou que ele a olhasse: se soube bonita, como uma modelo de Botero. Tinha aprendido a dançar no Carnaval do Rio, quando passava as férias na praia em busca de aventura, porque naquele tempo estava interessada em pescar, não em caçar, como agora.

Quando chegou um pouco perto demais, Diana percebeu o medo passando pelos olhos dele, mas anulou qualquer resistência olhando-o intensamente e pedindo que tivesse coragem porque o que viria era, realmente, o ponto alto. Ele tentou se sobrepor ao contato de uma língua estranhamente doce sobre seu sexo, ainda que se pudesse ver o esforço que fazia para manter a dignidade, até que ela avançou tanto que ele não teve outra alternativa a não ser se entregar.

Diana tirou o que lhe restava de roupa - uma camisa listrada - e montou por cima dele. Ele mal conseguiu balbuciar que ela o estava machucando. Pouco depois, sufocado, conseguiu dizer que estava sem ar, e só mais tarde implorou, com voz entrecortada, que ela desmontasse porque o estava asfixiando. Mas ela continuou em cima dele, cavalgando cada vez mais forte, e, a ponto de gozar, tapou-lhe a boca para não escutar os gemidos. Foi assim que os dois estremeceram juntos. 
Somente quando constatou que o homem estava inerte, desceu e tocou a campainha. Galia abriu a porta timidamente e perguntou, com sua voz de menina que mal dava para escutar: Pronto? Ainda nua, extenuada, Diana fez que sim com a cabeça. E então Galia deu passagem a Verena.

Com o olhar perdido, Verena caminhou até o sofá onde estava o corpo quente do homem. Ajoelhou-se a seus pés e abriu a maleta de couro cinza. Tirou as facas de aço damasco compradas em Toledo e as limpou minuciosamente, uma por uma, com gaze. Depois começou o trabalho. Não tinha tempo a perder, pois estavam sem mercadoria desde a semana anterior. Era preciso trabalhar rápido, deixar o corpo resfriar a noite toda ao sereno e preparar a comida para o jantar de sábado, sempre o mais concorrido.

\section{REFERÊNCIA}

ANDRUETTO, María Teresa. Cacería. Buenos Aires: Mondadori, 2012.

\footnotetext{
* Nylcéa Thereza de Siqueira PEDRA - Licenciada em Espanhol (1999) pela Universidade Federal do Paraná. Mestre em Letras (2003) pela mesma instituição e Mestre em Filologia Hispânica (2003) pelo Consejo Superior de Investigaciones Científicas, Espanha. Doutora em Letras (2010) pela Universidade Federal do Paraná. Professora da Universidade Federal do Paraná. Universidade Federal do Paraná, Setor de Ciências Humanas, Departamento de Letras Estrangeiras Modernas. Curitiba, Paraná, Brasil.

Currículo acadêmico: http://lattes.cnpq.br/3384979297707711

ORCID: https://orcid.org/0000-0003-1088-4260

E-mail: npedra@hotmail.com
}

${ }^{1}$ A tradução e sua publicação foram autorizadas pela Agencia Literária CBQ à tradutora Nylcéa Thereza de Siqueira Pedra em março de 2019. 